\title{
Where Is This Undergraduate Research Wave Taking Us?
}

\author{
Mark Benvenuto \\ Department of Chemistry and Biochemistry \\ University of Detroit Mercy \\ 4001 W. McNichols Road \\ Detroit, Michigan 48219-0900 USA
}

The last two decades have seen a large shift among the faculty of science departments as well as engineering departments, towards engaging undergraduate students in the research endeavor. A number of departments believe that some form of undergraduate-level research should be required of all students within their programs, others merely recommend it. Few exclude it from their curriculum outright. Recently, debate has begun on how early in a student's curriculum he or she should begin research. There is also considerable discussion as to whether undergraduate research is "real" research, or some exercise that needs to be relegated to an informal second tier of scientific work and inquiry.

As far as when a student should start, my experience has taught me that the decision is made on a case-by-case basis. Any research endeavor, whether it involves an undergraduate or a graduate researcher, is essentially an informal contract between a professor and a student. When it comes to undergraduate students, some are more mature than others (as in any group of people). Some are ready to undertake a research project at an earlier point in their college years than others. I have taken the occasional student into my research group as early as the second semester of their freshman year. Such students are always highly motivated, and manage their time well.

There are a couple of special considerations, or perhaps I should say duties, on the part of a faculty member when bringing an undergraduate into their research group. The first is to ensure that any project given to the student is one that can be dissected into small enough units that the student can work it into their schedule. Reactions that require constant monitoring over the course of ten hours or more simply aren't going to be completed by a student who must fit research in among five other classes.

The second faculty duty is proper supervision and mentoring. This means different things to different people, but it is fair to say that a new undergraduate probably needs more advice and oversight when in the lab than does a graduate student or post-doctoral fellow. This isn't just a matter of safety; it's a matter of teaching all the little techniques and tricks that are never written in books. It's mentoring that ensures the student learns how to function in the lab, or get their lab "hands." I have found that arguably the most important aspect of this is the speech I give to any new student. I never fail to point out that in other course and lab work, when a student makes a mistake or in some way fouls a piece of equipment, the natural reaction is to in some way hide what happened. I point out that embarrassing as it may be when something goes wrong, they need to come to me and relate exactly what happened. Only then can we work together to fix what is gone awry. To make this strange pep talk more realistic, I tell a story about a gross error I made as a first year graduate student (no, I emphatically will NOT repeat it here!), how I sheepishly told my advisor, and how the problem was fixed. Knowing that their professor is human seems to lessen my students' fear when something does go wrong.

The third faculty duty towards their undergraduate researchers is ensuring they get some experience presenting the results of their work. A publication in AJUR or another refereed journal may not always be a possibility, depending on how complete a 
project is when a student has to move on or to graduate. But there is almost always some local or regional scientific forum in which the student can present a talk or poster of his or her work. I have found that such an exercise gives my undergraduate researchers real confidence that what they have done during a semester is worthwhile and respected within the scientific community.

Research with undergraduate students though is far more than a series of obligations or jobs. It remains the pursuit of answers to questions that are only now being posed. That means undergraduate research shouldn't be some second tier exercise. It is and remains "real" work, often in a laboratory. Research represents that point in a person's education where they take ownership of what they are doing. In classes and teaching laboratories for the most part, education is what is presented to a student. But when that education evolves into research the student becomes the driving force. They go from being some form of passive learner to the most active of learners. The project is theirs. The results are theirs. The pride in what they are doing is theirs.

If research at an undergraduate level is as real and as capable of producing first-rate results as that done on a graduate level, one question that then arises is, where should such scholarly work be disseminated? The answer has to be, at any scientific conference or in any refereed journal. Certainly there is and probably always will be a totem pole of publication prestige, with both students and faculty wanting to land the results of their work as high on that pole as possible. But with the growth of the amount of research being conducted at colleges and institutes throughout the developed world, the older, more established journals end up yielding space to the newer journals and publications simply because they have page limits. This in turn means the newer journals move up in prestige, as more and more scientists, educators, and researchers see the value of the results presented in them. High marks go to publications like AJUR, that survive their first year (the most critical one) and continue to grow and flourish. Such publications play a vital part in providing a venue for the growing number of undergraduate researchers to communicate their results.

Where is this trend taking us then, of more undergraduates starting on some form of meaningful, scholarly research earlier in their college years? It appears to be part of a greater, slow change in education within the sciences and engineering. It seems we are moving to a curriculum with less formal lecture in it, and more hands on learning, which includes scholarly research. Decades from now I think this may be called a revolution in that sort of hindsight, but it will appear to be an evolution to those of us who build careers as it occurs. I, like many other faculty members, took a position envisioning any research group I might build being made up primarily of graduate students, and being funded by different granting agencies. But the reality has been a research group progressively filled with more undergraduate students, many of them with keen minds and plenty of energy. I have been thrilled repeatedly with their results, find their questions insightful and refreshing, and see them accepted by graduate students as their equals in the lab. I like this slow evolution, and am glad to be a part of it. I think that undergraduate research experiences create intellectually stronger graduates, and hope this trend continues to widen and grow.

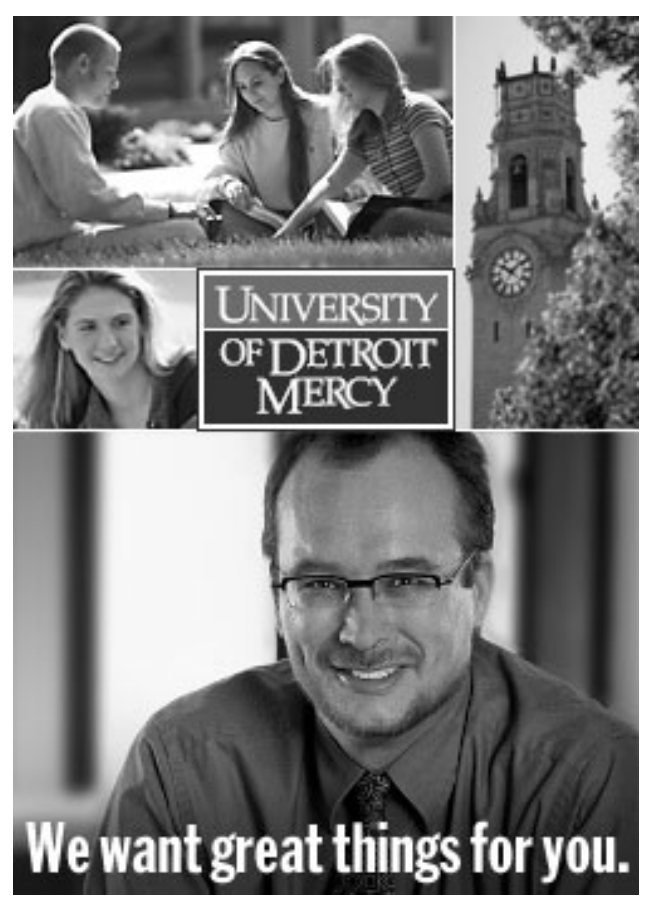

